\title{
Nanotechnology-enabled materials for hemostatic and anti-infection treatments in orthopedic
} surgery

This article was published in the following Dove Press journal: International Journal of Nanomedicine

\author{
Haolin Sun ${ }^{1,2, *}$ \\ Lu Lv $v^{3, *}$ \\ Yanjie $\mathrm{Bai}^{4, *}$ \\ Huilin Yang ${ }^{2,3}$ \\ Huan Zhou ${ }^{2,5}$ \\ Chunde $\mathrm{Li}^{\prime}$ \\ Lei Yang ${ }^{2,3}$
}

'Department of Orthopaedics, Peking University First Hospital, Beijing

100034, China; ${ }^{2}$ International Research Center for Translational Orthopaedics (IRCTO), Soochow University, Suzhou 215006, China; ${ }^{3}$ Orthopaedic Institute and Department of Orthopaedics, Soochow University, Suzhou 215006, China; ${ }^{4}$ School of Public Health, Medical College, Soochow University, Suzhou 215000, China; ${ }^{5}$ School of Mechanical Engineering, Jiangsu University of Technology, Changzhou 2I300I, China

*These authors contributed equally to this work

Correspondence: Lei Yang Orthopaedic Institute and Department of Orthopaedics, Soochow University, 708 Renmin Road, Suzhou 215006, China Email leiy@suda.edu.cn

Chunde Li

Department of Orthopaedics, Peking University First Hospital, 8 Xishiku

Street, Beijing 100034, China

Email chundeli@yeah.cn

\begin{abstract}
The hemostatic and anti-infection treatments in the field of orthopedics are always the pivotal yet challenging topics. In the first part of this review, synthesized or naturally derived nanoscale agents and materials for hemostatic treatment in orthopedic surgery are introduced. The hemostatic mechanisms and the safety concerns of these nanotechnology-enabled materials are discussed. Beside the materials to meet hemostatic needs in orthopedic surgery, the need for antimicrobial or anti-infection strategy in orthopedic surgery also becomes urgent. Nanosilver and its derivatives have the most consistent anti-infective effect and thus high translational potential for clinical applications. In the second part, the factors affecting the antimicrobial effect of nanosilver and its application status are summarized. Finally, the status and translational potential of various nanotechnology-enabled materials and agents for hemostatic and anti-infective treatments in orthopedic surgery are discussed.
\end{abstract}

Keywords: nanotechnology, hemostatic, antimicrobial, orthopedic surgery

\section{Introduction}

The emergence of nanotechnology, which explores and utilizes the properties of materials altered tremendously on the nanoscale $\left(1-100 \mathrm{~nm}\right.$ or $\left.10^{-9}-10^{-7} \mathrm{~m}\right)$ or atomic scale, brings in extraordinary opportunities and also challenges in medical science and biomedical engineering fields. ${ }^{1}$ National Institutes of Health reviewed the applications of nanotechnology for monitoring, diagnosis, and treatment of human diseases and has therefore introduced the term "nanomedicine" to describe these applications. ${ }^{2}$ Nanotechnology has offered a variety of new therapeutic and diagnostic options for orthopedic clinical practices and new approaches for improving the performance of current orthopedic implants. Recently, there is growing interest in the utilization of nanotechnology for hemostatic and anti-infective treatments in orthopedic surgery, which has exhibited large potential and promise for translational research and clinical applications.

Blood is responsible for transport of gases and nutrients to organs and tissues as well as providing immune surveillance and hemostatic responses as needed. Hence, loss of blood can result in a variety of pathologic scenarios that cause tissue morbidities and mortalities. ${ }^{3}$ For hemostatic purpose, nanomaterials have been reported to possess a number of physicochemical properties (such as chemistry, particle size, geometry, charges, and surface properties) that can vigorously influence the components of the coagulation system. ${ }^{4}$ For example, nanoparticles with sizes $<100 \mathrm{~nm}$ have superior penetration ability, resulting in fast cellular uptake and contact activation of coagulation 
factors. Nanomaterial surface charge can also induce cell membrane damage or alter protein interactions that relate to contact activation or depletion of coagulation factors. The shape of nanoparticles can also affect cellular uptake and penetration in the intracellular structures of blood cells. These factors together with the nanomaterial composition have been reported to cause toxicity, induction of inflammation, and generation of oxidative stress. ${ }^{4}$

In addition to hemostatic problem, postoperative infection associated with medical implants emerges as a formidable but critical problem in orthopedic surgery and therefore stimulates many researches in the nanotechnology field. In terms of antimicrobial effect, nanosilver has the well-established, consistent efficacy and therefore the most translational potential among nanomaterials. Nanosilver has been used for the treatment of burns and also in some dental and urological practices. ${ }^{5-7}$ Prototypes of nanosilver anti-infective products like nanosilver dressing have also been developed. ${ }^{8}$ Nanotechnology-enabled dressing has shown numerous benefits including strong adhesion to tissue, easy to mold, and preventing infection while promoting wound repair.

In the past decade, there are significant progresses in the hemostatic nanotechnology and anti-infective nanosilver for orthopedic surgery. This article reviews the progresses and advances in these fields and summarizes the understanding of possible mechanisms underlying the improved performance of such nanotechnology-enabled materials. Translational potential and important safety concerns related to these nanomaterials are also discussed.

\section{Nanotechnology-enabled hemostatic materials \\ Naturally derived nanomaterials \\ Oxidized cellulose}

Traditional oxidized cellulose hemostatic materials suffer from the disadvantages of low specific surface area, water insolubility, and slow hemostasis performance due to single hemostatic mechanism. ${ }^{9}$ A new nanotechnology-enabled oxidized cellulose hemostatic material alters the surface layer structure of the oxidized cellulose that contains nanosized oxidized regenerated cellulose sodium and collagen particles. The porosity of this nano-sized material reaches as high as $90 \%$, and this sponge-like material has a better hemostatic effect than normal and even surgical gauzes. Due to the porous structure, the amount of blood absorbed by the oxidized cellulose hemostatic nanomaterial is superior to ordinary ones, which can reduce the incidence of postoperative hematoma. ${ }^{9}$ This nanomaterial is shown to significantly shorten bleeding time and clotting time in a rabbit model and is expected to reduce the bleeding time in surgical operation as well as the overall operation time. In addition, further studies on nanocellulose have reduced the defects in the structure and increased its water solubility by surface modification methods such as two-step oxidation and alkalization and physical method of mechanical processing. These processes prevent the formation of strong hydrogen bonds within the cellulose, causing the adhesion between the cellulose polymer chains to decrease. ${ }^{9}$

Oxidized cellulose has also been fabricated into bioabsorbable hemostatic nanomaterials. ${ }^{10}$ Soluble oxidized cellulose or oxidized regenerated cellulose are used as substrates to dissolve base material and underwent high pressure filtration to obtain nanoparticles with sizes between 10 and $500 \mathrm{~nm}$. The nanoparticles are then concentrated in vacuum, wind-dried, and then sifted to obtain nano- to microcrystalline particles. The resultant nanomaterials are bioabsorbable and suitable to meet the hemostatic needs of various types of surgical wounds, especially the wound with long and narrow shapes that need minimally invasive surgery. In these complex scenarios, the nanomaterials can be easily delivered to the wound site through a pipeline spraying device and are effective and convenient to stop bleeding. ${ }^{10}$

\section{Halloysite nanotube (HNT)/chitosan nanocomposite}

HNTs, nanotube-like natural mineral, have also demonstrated great potential in wound management and surgical applications due to their high mechanical strength, acceptable biocompatibility, hemostatic property, and wound-healing ability. ${ }^{11}$ Whole-blood clotting experiment suggests that HNTs can increase the blood clotting rates of naturally derived chitosan, so HNT/chitosan nanocomposite has been developed. The nanocomposite sponges with $67 \%$ HNTs shows an $89.0 \%$ increase in the clotting ability compared with pure chitosan. Flexible 3D porous HNT/chitosan nanocomposite has also been developed. Biological evaluations of the nanocomposite revealed good cytocompatibility by fibroblasts and endothelial cells and enhanced blood clotting and platelet activation ability compared with chitosan and controls. ${ }^{11}$

\section{Nanofibrous membrane of carbonized hair}

Chinese herbal medicine criniscarbonisatus is essentially the carbide of human hair, and pharmacological studies reveal its benefits in blood clotting, vascular embolization, and antibacterial effect. ${ }^{12}$ Cost-efficient criniscarbonisatus is loaded to nanofibrous membrane by electrospinning technique. The 
porous structure of the nanofibrous membrane facilitates the exchange of nutrients and oxygen near wound site, promotes the repair of tissue damages in the wound area, and restores normal functions of tissue. The high specific surface area and porous structure of nanofibrous membrane are also favorable for cell adhesion, extension, proliferation, and differentiation. Criniscarbonisatus nanofibrous membrane, therefore, has several advantages including strong hemostatic effect, nontoxicity, and anti-infective capacities, ${ }^{13}$ revealing high potential for hemostasis management and broad applications in orthopedic surgery like trauma treatments. For example, compared with medical gauzes or absorbable gelatin sponges, nanofibrous membrane of carbonized hair was shown to significantly reduce the bleeding time in hemorrhage models of rabbit ear vein or liver and decrease the volume of bleeding in the liver hemorrhage model. Hemostasis study also revealed that this nanomaterial induced no significant pathological change around the liver and spleen. ${ }^{14}$

\section{Synthetic hemostatic nanomaterials}

Mesoporous silica-based xerogels

Novel $\mathrm{Ca} / \mathrm{P}$-containing mesoporous silica-based xerogels (also known as CaMXS) with good biodegradability and low heat generation have been developed for hemorrhage control. ${ }^{15}$ This type of hemostatic nanomaterial possesses uniform tunable nanopores (sizes less than $50 \mathrm{~nm}$ ) and high specific surface areas (up to $1,400 \mathrm{~m}^{2} / \mathrm{g}$ ) and high biodegradability. ${ }^{16}$ CaMXS exhibited good coagulation function evaluated by whole blood and accelerated both the intrinsic and extrinsic coagulation processes. The large specific surface area and $\mathrm{Ca} / \mathrm{P}$ components of CaMXS are mainly responsible for the hemostatic capacity. Similar mesoporous silica xerogels can be used for hemostasis management in various bleeding scenarios, including slow and rapid bleeding, and especially suitable for bleeding in the bone defect.

On the one hand, the great surface area and water adsorption capability of the silica-based xerogel can rapidly counterbalance the hydration heat energy to overcome the disadvantages of exothermic zeolite materials when contacting with blood..$^{15,17,18}$ On the other hand, tailored mesoporous structure and pore sizes are attributed to the superfast hemostatic effects of nanomesoporous molecular sieves. Silicabased xerogel is also a biologically active and biodegradable material; it can release Si ions during degradation and the proper concentration of released $\mathrm{Si}$ ions is known to stimulate bone cell functions and accelerate bone healing. In addition, the mesoporous structure can be used to load drugs, thrombin, and other bioactive factors to further improve the hemostatic and therapeutic effects. ${ }^{16}$

\section{Self-assembled peptides}

Nanostructured self-assembled peptides are another category of promising nanomaterials that have been designed and developed for hemostasis application. ${ }^{19-21}$ For example, peptide sequence RADA16 (AcN-RADARADARADARADACONH2) is a widely studied formula. ${ }^{22,23}$ When anion strength is increased or the external $\mathrm{pH}$ value is raised to neutral mimicking the physiological condition, the peptides spontaneously self-assemble into a 3D hydrogel scaffold ${ }^{24,25}$ and they may interweave into a 3D nanofiber matrix and form a jelly-like hydrogel. ${ }^{26,27}$ Another synthetic self-assembling peptide AC5 might also become a critical tool to rapidly and safely stop bleeding even in the presence of anticoagulation agent, which is reported to effectively shorten the time of surgery. ${ }^{28}$ AC5 could achieve hemostasis in $<30$ seconds in the brain, spinal cord, liver, femoral artery, and skin of small animals. ${ }^{28,29}$

AC5 acts as a simple barrier without interacting with or being influenced by the clotting cascade and it appears to provide effective hemostasis without harming surrounding tissues or cells, including red blood cells (RBCs). AC5 does not rely on heat, pressure, platelet activation, adhesion, vasoconstriction, or desiccation to stop bleeding. The material, which initially is a water-like liquid, turns to a gel when contacting with bodily fluid. It is biocompatible, and its biodegradation products are natural and can be used by the body to rebuild tissue or excreted in the urine. This nanomaterial can be injected or sprayed at the required location, allowing for minimally invasive surgery and prophylactic applications. Furthermore, AC5 easily fills in and conforms to the irregular shapes of the wounds before assembling and does not cause adverse immune response or direct tissue damage. ${ }^{28-30}$

\section{Ethylene oxide and propylene oxide gels with nanohydroxyapatite/alginate}

Bioactive hydroxyapatite (HAp), a main component in human skeletal bone, ${ }^{31}$ and alginate (AG), a natural polysaccharide extracted from brown sea algae, are biocompatible, hydrophilic, and biodegradable under physiological conditions. Sponge-like AG that is formed by cross-linking in the presence of calcium ions possesses hemostatic effect. ${ }^{32,33}$ In a study, porous spherical nano-HAp/AG granules was combined with ethylene oxide $\left(\mathrm{C}_{2} \mathrm{H}_{4} \mathrm{O}\right)$ and propylene oxide $\left(\mathrm{CH}_{3} \mathrm{CHCH}_{2} \mathrm{O}\right)(\mathrm{EPO})$ gel, a biodegradable material used for 
protein purification, ${ }^{34}$ to form a new hemostatic nanomaterial. The stanching effect on blood was evaluated on pure EPO and the nanomaterials and results indicated that the stanching times were $\sim 5$ and 11 hours for EPO gels containing nano$\mathrm{HAp} / \mathrm{AG}$ granules and pure EPO gel, respectively. Also, the time of the nanomaterials for stanching blood is satisfactory to meet the need for surgery. ${ }^{35}$

\section{Polyphosphate-bound gold colloids}

A number of blood coagulation studies indicate that polyphosphate-bound gold nanoparticles can effectively shorten blood clotting time and have many advantages for localized internal hemorrhaging treatments. ${ }^{36}$ Studies have shown that gold nanoparticles are the optimal core to bind polyphosphate chains. Gold nanoparticles exhibit promising stability at neutral $\mathrm{pH}$ in water and are more effective or stable than dendrimers or polystyrene to bind polyphosphate. Studies show that nanoparticles $>50 \mathrm{~nm}$ have the potential to further enhance blood clotting kinetics through contact pathways, and concentrated gold nanoparticles appear to yield higher concentrations of polyphosphate and can also shorten the time to clot. Also the combination of intrinsic and extrinsic pathways by using functionalized polyphosphate gold nanoparticles opens a very promising avenue to develop an intelligent treatment for internal hemorrhaging. ${ }^{36}$

\section{Nanofibrous gelatin membrane}

Remonda et $\mathrm{al}^{37}$ and Coln et $\mathrm{al}^{38}$ have long reported the excellent hemostatic effect of collagen. Gelatin is a partially hydrolyzed collagen with good hemostatic property, biocompatibility, and biodegradability and has obvious cost advantages compared with collagen. Hemostatic mechanism of gelatin includes the adhesion and activation of platelets which promote blood clot formation to stop bleeding. A new hemostatic agent ${ }^{39}$ showed the same biochemical crosslinking chemistry as the final stages of the blood coagulation cascade while using gelatin as a "structural" protein (rather than fibrin). In rat liver hemostasis models, the hemostatic agent showed a similar hemostatic effect as that of SURGIFLO ${ }^{\circledR}$ (as positive control) but higher adhesion strength and elasticity than SURGIFLO ${ }^{\circledR}$.

\section{Single-walled carbon nanotubes (SWNTs)}

In recent years, many studies have been devoted to the investigation of the interaction between carbon nanotubes and blood proteins and cells. ${ }^{40}$ In particular, it has been shown that SWNTs added either to isolated platelets or platelet-rich plasma can stimulate platelets to aggregate. ${ }^{37,41-43}$ Studies have also shown that SWNTs interact simultaneously with many factors of hemostasis, and their effect on blood coagulation is not only limited to inducing platelet aggregation. Further study on modified SWNTs showed that carboxylated SWNT shortens the clot formation time five times compared with the platelet-poor plasma. ${ }^{44}$ Interestingly, when administrated into bloodstream of animals, functionalized SWNTs exhibit procoagulant and pro-aggregating properties and diminish their negative influence on blood cells. These promising effects for hemostasis applications could be attributed to the significant changes in nanotube surface properties and interaction between nanotubes and cells after surface modification or functionalization of SWNTs. ${ }^{44}$

\section{$\mathrm{TiO}_{2}$ nanotubes}

Typically, $\mathrm{TiO}_{2}$ nanotubes can be readily prepared by anodization of titanium in an electrolyte comprising dimethyl sulfoxide and HF and then dispersed by sonication if needed. Studies on the interaction between blood and $\mathrm{TiO}_{2}$ nanotubes demonstrate significantly stronger clot formation at reduced clotting times when compared with pure blood. ${ }^{45} \mathrm{TiO}_{2}$ nanotubes are found to act as a bioactive scaffold to facilitate fibrin formation. These understandings suggest that $\mathrm{TiO}_{2}$ nanotube-functionalized bandage could be used to stimulate fast hemostasis or stop hemorrhage. In details, studies indicate that the activated clotting time of blood was reduced approximately by $10 \%$ (from 285 seconds for pure blood to 260 seconds) when blood was in contact with nanotubedecorated gauze bandages or with nanotubes directly. Also the blood directly in contact with nanotubes was found to have increased blood clot strength by $\sim 75 \%$ (from $2.21 \mathrm{kPa}$ for pure blood to $3.87 \mathrm{kPa}$ for blood containing $1 \mathrm{mg} / \mathrm{mL}$ of nanotubes), suggesting that the gauze bandages decorated with $\mathrm{TiO}_{2}$ nanotubes could improve both the rate of blood clot formation and the strength of blood clot. ${ }^{45}$

\section{Synthetic platelets based on Arg-Gly-Asp- functionalized nanoparticles}

Natural platelets have a short shelf life and the administration of allogeneic platelets can cause graft-versus-host diseases, alloimmunization, and transfusion-associated lung injuries. ${ }^{46}$ An approach of synthetic platelets based on functionalized nanoparticles that bind to activated platelets to augment clotting in a safe localized manner has been developed. This nanosystem leverages existing biological processes by providing a nanostructure that binds to activated platelets and enhances their rate of aggregation and subsequently stops bleeding. The synthetic platelets halved bleeding time after intravenous administration in the femoral artery injury model, and it performed significantly better than activated recombinant factor VIIa, which is currently used in the 
clinics for managing uncontrolled bleeding. It was reported that nanospheres functionalized with polyethylene glycol (PEG) branches with a molecular weight of 4,600 Da and the Gly-Arg-Gly-Asp-Ser moiety led to the greatest platelet adhesion and aggregation in vivo. ${ }^{47}$

\section{nHA-graft-poly(D,L-lactide) nanocomposite}

nHA-g-poly(D,L-lactide) (PDLLA) nanocomposites were synthesized by in situ grafting polymerization of DLLA from the surface of HAp nanoparticles (also known as nHA) under argon atmosphere according to previous works. ${ }^{48,49}$ The surface morphology and porous structures of nHA-g-PDLLA nanocomposite microspheres can be well controlled by both alkaline treatment and nanocomposite composition, allowing nHA-g-PDLLA microspheres to possess huge specific surface area to activate blood clotting. ${ }^{50}$ It was found that the number of platelets adhered onto the nanocomposite microspheres increased with increasing alkaline treatment time. The inorganic HA nanoparticles and their exposures on the pore surface also played an important role in platelet adhesion as well. They not only strongly absorb protein constituents in blood but also release high $\mathrm{Ca}^{2+}$ concentration for greatly accelerating the coagulation cascade. Specifically, $\mathrm{Ca}^{2+}$ ions promote the secretion of hemostatic mediators of platelets ${ }^{51,52}$ and the transformation of fibrinogen to fibrin. ${ }^{50,51}$

\section{Hemostatic mechanisms of nanomaterials}

Table 1 provides an "at-a-glance" summary of various representative hemostatic materials along with characteristic evaluations. ${ }^{53}$ Figure 1 shows the morphology of several hemostatic materials, ${ }^{15,35,54}$ many of which have been reviewed in the previous section. In this section, understandings of important hemostatic mechanisms of nanomaterials are discussed, beginning with a brief review of the physiology of hemostatic procedure.

The blood coagulation balance is achieved by the interaction of the blood platelets with the plasma coagulation system and the vascular endothelial cells. In healthy organism, these systems prevent thrombosis and, in the events of vascular damage, enable blood clotting to stop bleeding. ${ }^{54}$ In the hemostatic procedure, the effect of coagulation factor is essential and can be categorized into three pathways. ${ }^{55,56}$ In the extrinsic coagulation pathway (ECP), tissue factor (TF) is released when tissue and blood vessels are damaged. TF forms a complex with the transformation of the accelerator precursors FVII or activated FVIIa (TF-FVIIa), which activates FX and FIX. It is believed that the ECP was first started in pathological coagulation. Once TF comes into the blood, the process of coagulation can be significantly promoted. ${ }^{56}$ In the intrinsic coagulation pathway, which is usually associated with vascular wall injury, subendothelial tissue components (collagen, etc. expose and FXII is activated by collagen into FXIIa; a small amount of FXIIa combined with high molecular weight kininogen (HMWK) then converts prekallikrein to kallikrein, which can quickly feedback-activate FXII with HMWK. The activated factor XII (FXIIa) reactivates FXI and FXIa, and ionized calcium $\left(\mathrm{Ca}^{2+}\right)$ reactivates FXI. FXIa forms a complex with $\mathrm{Ca}^{2+}$, FVIIIa (activated by thrombin), and PF3 (phosphatidylserine), which activates

Table I An "at-a-glance" summary of various representative hemostatic materials

\begin{tabular}{|c|c|c|c|c|}
\hline Materials & $\begin{array}{l}\text { Fibrin glue and } \\
\text { collagen sponge } \\
\text { (biological products) }^{37,38,50}\end{array}$ & $\begin{array}{l}\text { Acrylates } \\
\text { (synthetic } \\
\text { products) }^{79,112}\end{array}$ & $\begin{array}{l}\text { Microporous } \\
\text { polysaccharide } \\
\text { hemospheres }^{18,33}\end{array}$ & Oxidized cellulose $e^{9,10}$ \\
\hline Origin & Animal origin & Chemical origin & \multicolumn{2}{|l|}{ Botanical origin } \\
\hline Mechanism & $\begin{array}{l}\text { Simulates endogenous } \\
\text { coagulation }\end{array}$ & $\begin{array}{l}\text { Mechanical } \\
\text { sealing }\end{array}$ & $\begin{array}{l}\text { Mechanical sealing and } \\
\text { simulates endogenous } \\
\text { coagulation }\end{array}$ & $\begin{array}{l}\text { Simulates endogenous } \\
\text { coagulation }\end{array}$ \\
\hline Working time & \multicolumn{2}{|l|}{$5-10$ minutes } & A few seconds & $5-10$ minutes \\
\hline Adhesive strength & \multicolumn{2}{|l|}{ High } & Very high & High \\
\hline Degradation/absorption & $2-6$ months & None & 3-5 days & $2-6$ months \\
\hline Hemostatic effect & \multicolumn{2}{|l|}{ Acceptable } & Very good & Acceptable \\
\hline Risk of virus infection & Medium & \multicolumn{3}{|l|}{ Low } \\
\hline Histocompatibility & High & Low & Very high & High \\
\hline Toxicity of degradation products & Very low & Medium & \multicolumn{2}{|l|}{ Very low } \\
\hline Side effects & $\begin{array}{l}\text { Immune reactions, } \\
\text { allergies, and other } \\
\text { animal-borne diseases }\end{array}$ & $\begin{array}{l}\text { Allergic reactions } \\
\text { and local formation } \\
\text { of induration }\end{array}$ & Not reported & $\begin{array}{l}\text { Decomposition of } \\
\text { acidic products may } \\
\text { affect tissues like nerve }\end{array}$ \\
\hline
\end{tabular}

Note: Data summarized from references $9,10,18,33,37,38,50,79,112$. 

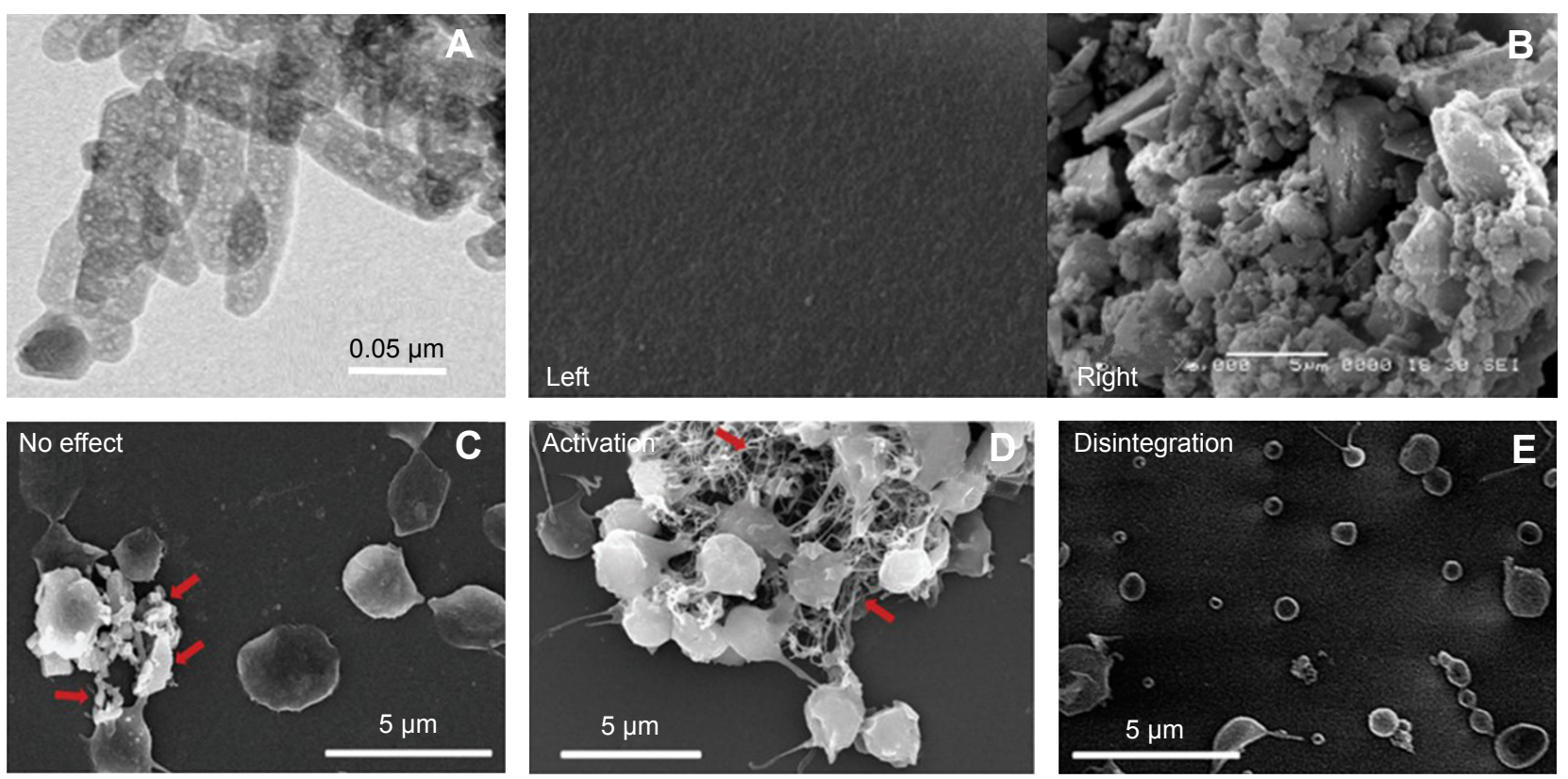

Figure I (A) TEM micrographs of HAp nanoparticles. The sizes of the rod-shaped primary particles were $\sim 30 \times 50 \mathrm{~nm}$. (B) Left: SEM image shows that almost no platelet was observed on the control group (i.e., silica-basement without the xerogels); Right: on the silica-based xerogels, the amount of platelets was dramatically increased on the CaMX. (C) Field-emission scanning electron microscopy (FESEM) image shows no effect or slight activation of platelets with C60 fullerene; and (D) FESEM image shows strong activation of platelets with multiwalled carbon nanotubes; (E) FESEM image shows disintegarion of platelets with aminoterminated PAMAM dendrimer. Red arrows indicate nanomaterials. Notes: (A) Adapted from Hama C, Umeda T, Musha Y, Koda S, Itatani K. Preparation of novel hemostatic material containing spherical porous hydroxyapatite/alginate granules. J Ceram Soc Japan. 20I0; I 8(I378):446-450. Creative Commons license and disclaimer available from: http://creativecommons.org/licenses/by/4.0/legalcode. ${ }^{35}$ (B) Republished with permission of Trans Tech Publications Ltd, from [Development of a novel CaP-containing mesoporous silica-based xerogels used as hemostatic material with good biodegradability and low heat generation, Li XS, Lin W, Xin FL, Yuan Y, Liu CS, Long Da C, vol 340, copyright 1994]; permission conveyed through Copyright Clearance Centre, Inc. ${ }^{15}$ (C) and (D) Copyright @2017. Dove Medical Press. Adapted from Simak J, De Paoli S. The effects of nanomaterials on blood coagulation in hemostasis and thrombosis. Wiley Interdiscip Rev Nanomed Nanobiotechnol. 20 I7;9(5):el448. ${ }^{54}$

Abbreviations: HAp, hydroxyapatite; TEM, transmission electron microscopy; SEM, scanning electron microscopy.

FX as FXa. It is thought that the initial thrombin directly activates FXI and converts FXI into FXIa. Beside, in the common coagulation pathway, activated FXa forms a complex prothrombin with PF3, $\mathrm{Ca}^{2+}$, and FVa (activated by thrombin). Prothrombinase converts prothrombin (FII) to thrombin (FIIa), and thrombin converts fibrinogen (Fg) to soluble fibrin monomer; thrombin activates FXIII into FXIIIa which causes sFMs molecule cross-linked to the insoluble and stable fibrin, resulting in blood coagulation..$^{56}$

Surface charge of nanoparticles has been proved to be strongly correlated with hemostasis. It is well known that chitosan and its derivatives are positively charged and readily form a cell thrombus or thrombus in combination with negatively charged red blood cells, white blood cells, and platelets, which promotes the secretion of glycosaminoglycans such as hyaluronic acid to speed up wound healing. ${ }^{57,58}$ Other materials like surgical hemostatic gauze made of oxidized cellulose or oxidized regenerated cellulose are based on the hemostatic mechanism in which the acidic carboxyl groups in the molecule and hemoglobin in the combination of $\mathrm{Fe}^{3+}$ ions form a sticky plastic block closing capillaries and bleeding, providing a matrix for platelets adhesion, aggregation, and activation of the body coagulation mechanism. ${ }^{59}$

\section{Safety concerns}

Although nanomaterials have demonstrated great potential in bleeding controls, there are increasing concerns about nanomaterial-induced coagulopathy. Several studies have reported that nanoparticles significantly increase the risk and worsen the prognosis of cardiovascular diseases due to the induction of thrombotic complications, ${ }^{60-63}$ which are serious in orthopedic surgery. In healthy individuals, the clot formation and fibrinolytic systems are highly regulated to ensure hemostatic balance, and any dysregulation can lead to impaired or weak clot formation (poor hemostasis and rebleeding) or overly strong occlusive clot growth (thrombosis). ${ }^{3}$ Unfortunately, there are an increasing number of studies reporting that engineered nanomaterials may shift the hemostatic balance by perturbation of the coagulation system, causing severe toxic effect. For example, disseminated intravascular coagulation, which is a common complication in sepsis and cancer and may lead to multiple organ failure and even to death when left untreated, has 
been reported with intravenous administration of certain nanomaterials such as cationic poly (amidoamine) dendrimers and amine-terminated dendrimers. ${ }^{64,65}$ Another common life-threatening coagulation disorder, deep vein thrombosis characterized by clot formation in deep veins, has also been reported to be associated with some nanomaterials like multiwalled carbon nanotubes. ${ }^{41}$

More caution should be given to the fact that nanoparticles may affect structure and functions of coagulation factors, endothelial cells, and platelets. ${ }^{66,67}$ In addition, each nanoparticle is unique, and adverse effects and mechanisms may vary, even for nanoparticles of the same category. ${ }^{67} \mathrm{~A}$ rule of thumb is that charged and hydrophobic materials are more reactive and often activate coagulation through noncanonical pathways. ${ }^{68}$

\section{Antimicrobial nanosilver for orthopedic surgery Antimicrobial effect of nanosilver}

Figure 2 shows the morphology of silver nanoparticles and bactericidal effect of nanosilver. ${ }^{103,116}$ Certain concentrations of silver nanoparticles reduce cell viability and increase reactive oxygen species production in Saos-2, but do not interfere with the response of the cells to the osteogenic factors. ${ }^{70}$ The antimicrobial properties of nanosilver are closely related to its structural characteristics. ${ }^{71}$ Nanosilver particles, which in general possess larger specific surface area than conventional silver particles, increase the likelihood to adhere to bacteria. Studies have revealed that the anisotropy of nanosilver, sizes, chemical composition, stability, and catalytic activity will affect the ability of nanosilver to release silver ions and adsorb into bacterial cell wall. ${ }^{71,72}$

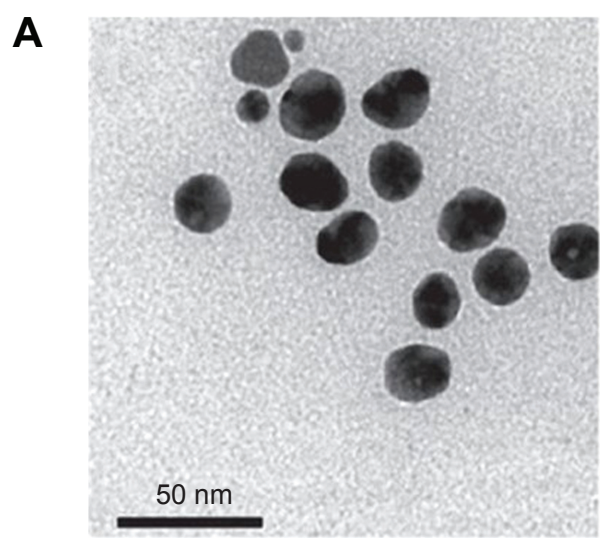

C
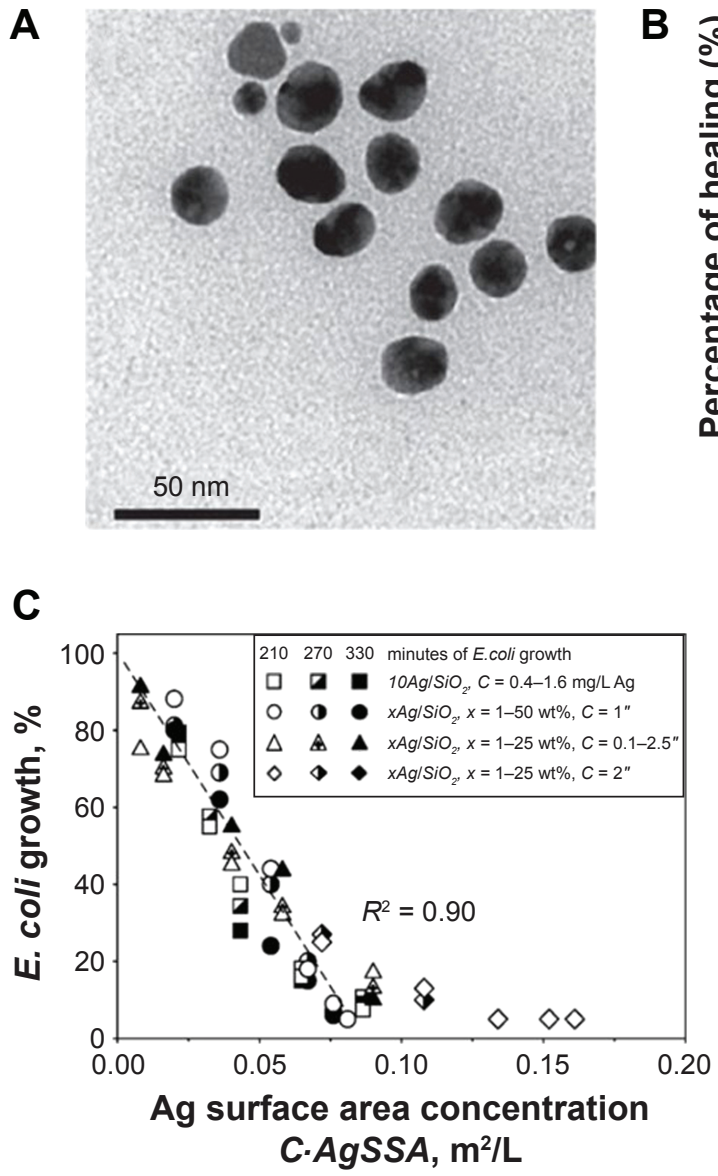

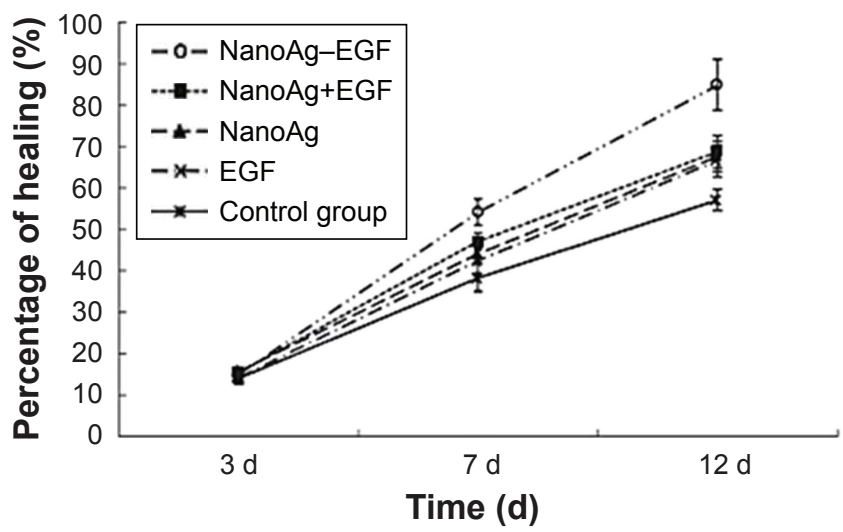

D

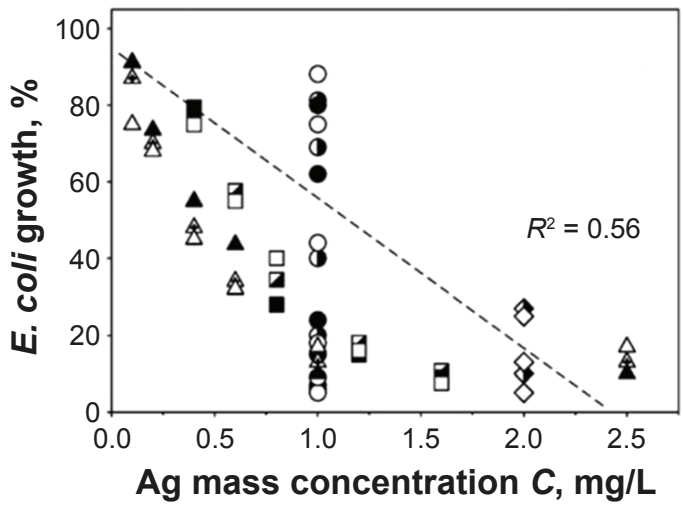

Figure 2 (A) TEM image of the silver nanoparticles (magnifcation $\times 500,000$ ). (B) Comparison of the wound-healing rate in each group at 3, 7 and 12 days post-trauma. EGF, epidermal growth factor. (C) The extent of E. coli growth of all data at 210, 270 and 330 min as a function of the silver surface area concentration C. AgSSA.; (D) The extent of $E$. coli growth of all data at 210,270 and 330 min as a function of the silver mass concentration $C$ in suspension.

Notes: (A) and (B) Copyright @20 I3. Dove Medical Press. Adapted from Zhou JD, Wang SH, Liu R, et al. Study of the biological effectiveness of a nanosilver-epidermal growth factor sustained-release carrier. Exp Ther Med. 20I3;5(4): I23I-1235. ${ }^{103}$ (C) and (D) Reprinted from Chemical Engineering Journal, vol 2-3, Sotiriou GA, Teleki A, Camenzind A, Krumeich K, Meyer A, Panke S, Pratsinis SE, Nanosilver on nanostructured silica: antibacterial activity and Ag surface area, pages 547-554, Copyright (20I I), with permission from Elsevier. ${ }^{116}$ Abbreviation: TEM, transmission electron microscopy. 
For example, it has been reported that the 111 crystal face of nanosilver is more easily combined with bacteria and has a stronger antibacterial activity, ${ }^{73}$ probably due to the higher atomic density and the stronger activity of silver atom on this crystal surface compared with others. Beside, research has shown that silver nanoparticles' surface exposed to oxygen will be oxidized into insoluble silver oxide, decreasing the release of silver ion thus affecting the antibacterial effect of silver nanoparticles. ${ }^{71}$

The antibacterial properties of silver nanoparticles vary with their particle sizes too. In principle, silver nanoparticles of $5 \pm 2 \mathrm{~nm}$ can enter the bacterial interior and nanoparticles less than $10 \mathrm{~nm}$ can adsorb on the surface of bacterial cell walls. ${ }^{74}$ The specific surface area and surface energy also dramatically increase when particle size decreases, which is also beneficial for the release of silver ions and thereby enhances the antibacterial activity of the silver. ${ }^{75}$ It is worth noting that, however, the surface potential of small-size silver nanoparticles is low and the electrostatic repulsion effect is limited, so the particles are easier to agglomerate and thus their antibacterial effect varies. ${ }^{76}$

A common solution to the problem that silver nanoparticles are prone to agglomeration is adding stabilizing agents such as sodium dodecyl sulfate, polyvinylpyrrolidone (PVP), chitosan, and cellulose to the preparation process of nanosilver. ${ }^{74}$ But the stabilizers have been shown to influence the antibacterial effect of silver nanoparticles. For example, the stabilizers containing large amount of hydroxyl groups and amino groups are beneficial to the dispersion of silver nanoparticles, but they also inhibit the diffusion of silver ions and weaken antibacterial activity. ${ }^{77}$ However, given the large variations in the size and morphology of silver nanoparticles prepared by different stabilizers, it is difficult to elucidate the effect of stabilizers on the antibacterial properties of the nanoparticles. ${ }^{74}$

At last, many studies suggest that silver nanoparticles themselves can be toxic to the cells and tissues, revealing a dose-dependent toxicity. ${ }^{78}$ So the reduction of the nanosilver concentration is always an important biosafety requirement before any human applications. ${ }^{79}$ Table 2 shows the evaluation of the antibacterial effect of nanosilver in vivo. ${ }^{80,81}$

\section{Current trends on the study of nanosilver}

\section{Green synthesis of nanosilver}

The present synthesis methods of nanosilver use a large amount of organic solvents, toxic reductants, or stabilizers, which brings great risks for environment, ecosystem, and future clinical applications. Green synthesis of silver nanoparticles becomes an important prerequisite for development and application of these nanomaterials. The strategy of green synthesis includes the usage of solvents with high biological safety like supercritical $\mathrm{CO}_{2},{ }^{82}$ mild reductants like starch or maltose, ${ }^{83}$ and nontoxic intermediates and stabilizers including gelatin. ${ }^{82,83}$ Many scholars have adopted reductants, such as glucose, starch, and maltose to prepare nanosilver. For example, Takeshima et $\mathrm{al}^{84}$ used DNA extracted from trout spermary as a reducing agent for the production of nanosilver with sizes $<10 \mathrm{~nm}$. Oluwafemi et $\mathrm{al}^{83}$ used silver nitrate, gelatin, and maltose as precursors, stabilizers, and reductants,

Table 2 In vivo evaluation of the antibacterial effect of nanosilver

\begin{tabular}{|l|l|l|l|l|l|}
\hline Evaluation & Samples & Experimental details & $\begin{array}{l}\text { Bacterial species } \\
\text { studied }\end{array}$ & Outcome \\
\hline Animal study & SD rats & $\begin{array}{l}\text { Skin defect created and } \\
\text { treatment was applied. } \\
\text { Wound healing was monitored } \\
\text { after 4, 7, I4, 2I, and 28 days }\end{array}$ & Acetobacter xylinum MI2 & $\begin{array}{l}\text { The wound healing in } \\
\text { the treatment group } \\
\text { was better, forming } \\
\text { thick granulation } \\
\text { tissue; fibroblasts and } \\
\text { vascular endothelial cells } \\
\text { proliferated; formed more } \\
\text { collagen fiber bundles; } \\
\text { angiogenesis in the dermis } \\
\text { was detected }\end{array}$ & 80 \\
\hline Clinical experiment & $\begin{array}{l}\text { Shallow II and } \\
\text { deep II burn } \\
\text { patients }\end{array}$ & $\begin{array}{l}\text { Attached nanosilver dressing } \\
\text { to the wound directly after } \\
\text { debridement and then bind with } \\
\text { sterile gauze. Wound healing } \\
\text { was observed and the bacteria } \\
\text { taken from wound were } \\
\text { cultured }\end{array}$ & $\begin{array}{l}\text { Common bacteria such } \\
\text { as Escherichia coli and } \\
\text { Staphylococcus aureus }\end{array}$ & $\begin{array}{l}\text { The bacterial detection } \\
\text { rate of the treatment } \\
\text { group decreased. } \\
\text { Wound healing period was } \\
\text { significantly shortened }\end{array}$ & $8 \mathrm{8I}$ \\
\hline
\end{tabular}


respectively, to synthesize a nanosilver with sizes $<5 \mathrm{~nm}$. The ingredients used in these synthetic methods are harmless to the human body.

\section{Extending the function of nanosilver}

Nanosilver has been further functionalized with other materials like chitosan and polyvinylpyrrolidone (PVP) to resist infection and repair wounds. ${ }^{79}$ Chitosan is reported to have good histocompatibility and biodegradability for the application of wound management, whereas PVP is a synthetic polymer with good histocompatibility. Both chitosan and PVP have been widely used in the preparation of plasma bulking agent, vitreous body fluid substitutes, and so on. Recent studies reported the antibacterial properties in the composites that combined nanosilver with chitosan and PVP. Archana et $\mathrm{al}^{85}$ showed that the slow release of silver ions, improved antibacterial effect and subsequently enhanced wound repair were achieved by the nanosilver wrapped with PVP and chitosan.

Propolis is a natural substance with antinflammatory, antioxidant, and antimicrobial properties. The nanosilver synthesized with addition of propolis in situ can reduce minimal inhibitory concentration of nanosilver and accelerate the healing of burn wounds in rats. ${ }^{86}$ Healing of burn wounds needs to exclude ultraviolet exposure in order to mitigate the adverse reactions such as scar hyperplasia. Arora et $\mathrm{al}^{87}$ showed that nanosilver with a size of $10-40 \mathrm{~nm}$ can protect the DNA of glial cells from UVB radiation damage, indicating that nanosilver may protect the burn wound from the impact of ultraviolet radiation. Compared with commercially available nanosilver products, nanosilver loaded with propolis, chitosan, and collagen has the advantages of promoting tissue repair, broadening antibacterial spectrum, and controllable release of silver ions. ${ }^{79}$

\section{Status and translational potential of nanotechnology-enabled agents and materials \\ Current hemostatic and anti-infective strategies in orthopedic surgery \\ Current hemostatic strategies in orthopedic surgery}

Perioperative bleeding and postsurgical hemorrhage are common in invasive surgical procedures, including orthopedic surgery. For example, spine surgery has typically been associated with significant blood loss and transfusion requirements. It is particularly common for multilevel spinal fusion, deformity correction, and anterior-posterior spinal fusion. Data further suggest that both bleeding and resultant transfusions are associated with an increased risk of adverse outcomes. ${ }^{88}$ As surgical volume increases, the ability to minimize the rates of intraoperative bleeding, postoperative anemia, and transfusion is becoming increasingly important to patients and the healthcare system. ${ }^{89}$

There are several currently used strategies for bleeding control and management. In traditional (Bovie) electrocautery, a unipolar device delivers an electrical current to tissues through a pencil-like instrument, and the intraoperative tissue temperatures can exceed $400{ }^{\circ} \mathrm{C} .{ }^{90}$ Bipolar sealer delivers radiofrequency energy through a saline medium, which increases the contact area, acts as an electrode, and maintains a cooler environment during electrocautery. Proposed advantages of this strategy includes reduced tissue destruction and absence of smoke..$^{90}$

\section{Current anti-infective strategies in orthopedic surgery}

Osteomyelitis has been reported in 9\% (14\% of intensive care unit patients), and deep-wound infection in $27 \%$ of type III open-tibia fractures during operations in Iraq and Afghanistan. ${ }^{91}$ Infection prevention during and after an orthopedic surgery relies largely on the control measures of surgical process and the use of antibiotics. The effective control measures of surgical process includes environmental management, equipment instrument disinfection and sterilization, the medical personnel hand hygiene, patient preoperative bath, temperature control, preoperative blood glucose control, operation duration, timing of surgery, and so on. These measures are common and proved to be highly effective to reduce the infection rate.

Management of acutely infected wounds is primarily surgical, relying on removal of remaining foreign bodies and debris, debridement of necrotic and devascularized tissue, and drainage of fluid collections. The antibiotics is also widely used. ${ }^{91}$ Beside, prophylactic systemic antibiotics are also administered routinely to patients who receive an orthopedic implant to prevent perioperative infection. However, systemic administration of antibiotics has many disadvantages including the increased risk of antibiotic resistance, the need for a correct timing of administration, the relatively low drug concentration at the target site, and the limited ability to kill bacteria eventually present on the implant surface or embedded in biofilms. ${ }^{92}$

Recent efforts include the development of novel antibiofilm implants equipped with nanoparticles. ${ }^{93}$ Besheli et al ${ }^{94}$ showed that silk fibroin nanoparticles are effective in treating severe osteomyelitis in a controlled animal study. Recently, researchers developed a titanium pedicle screw coated with silver nanoparticles which could inhibit biofilm formation on the implanted screws in rabbits. ${ }^{95}$ Nanotechnology-enabled infection control has demonstrated substantial promise to 
prevent acute postoperative infections in trauma and spinal implants in addition to joint replacements. ${ }^{93}$

\section{Translational potential of nanotechnology-enabled hemostatic and anti-infection agents and materials}

In the past few years, there have been surgical biomaterials containing nanoparticles or having a distinct nanotopography on the translational paths toward commercial products of a new generation of surgical materials with enhanced functionality. ${ }^{96}$ For example, recent advancements in nano technologies have touched the field of tissue adhesives by either introducing new functionalities including hemostatic or antibacterial properties or improving their mechanical properties as well as their adhesion force to surrounding tissues. Specifically, silica and iron oxide nanoparticles were used to develop hemostatic and wound closure materials. ${ }^{97}$ Nanoparticles with antibacterial and hemostatic properties have been incorporated into polymeric adhesives to reduce the risk of infections or hemorrhage after surgeries. ${ }^{96}$

In the orthopedic surgeries like fracture incision internal fixation, joint replacement, and spinal operation, nanomaterials have exhibited great potential for the uses in the hemostatic procedure during these surgeries. For example, a number of naturally derived hemostatic agents or materials (e.g., nanosized oxide regenerated cellulose, halloysite chitosan nanotubes, nanofiber tunic carbonized hair) and synthesized hemostatic materials (e.g., mesoporous silicabased xerogels, self-assembling peptides, gelatin nanofibrous membrane) have been developed and completed preclinical evaluations. However, neither there are commercially available products of nano hemostatic agents nor anyone entered the phase of clinical trials.

Orthopedic implants have revolutionized treatment of bone fractures and noninfectious joint arthritis. Today, the risk for orthopedic device-related infection (ODRI) is $<1 \%-2 \%$. However, the absolute number of patients with infection continuously increases as the number of patients requiring such implants grows. Treatment of ODRIs most frequently includes long-term antimicrobial treatment and removal of the implant. ${ }^{98}$ Nowadays, the use of intra-wound antibiotics (eg, vancomycin) is becoming a standard procedure to prevent infections like spinal surgical site infection.

On the aspect of anti-infection applications, attempts to bestow the implant surface with antibacterial functionality have been widely considered for commercial applications. For less regulatory risks from medical device administrations, many translational studies have focused on controlling the biological response to orthopedic implants by altering surface structure and topology of the biomaterials. ${ }^{99,100}$ In this regard, changing the implant surface at a nanometric scale, at which bacterial adhesion does not simply follow the roughness of the surface but is also dependent on other variables like the quantity of adsorbed proteins, can in fact suppress bacteria adhesion. ${ }^{92,101}$ The products based on this strategy are currently in the process of commercialization.

A number of companies are now actively developing nanosilver as an alternative antibacterial agent of antibiotics for various orthopedic applications. However, high concentration of nanosilver has been demonstrated to be cytotoxic and genotoxic to mammalian cells; ${ }^{102}$ so, achieving controllable release of nanosilver has become a major hurdle for the translation and commercialization of nanosilver products. Current research efforts focus on the selection and optimization of nanosilver carriers. For example, a nanosilver-EGF sustained-release carrier was developed. ${ }^{103}$ A nanosilver release system exhibited potential to be used in anti-infective bone cement to fill bone voids and to treat vertebral compression fractures. ${ }^{104,105}$ In another example, nanosilver modified diatomite (AgDT) has been developed by depositing silver nanoparticles uniformly on the surface of natural diatomite disk, achieving a prolonged and uniform release of $\mathrm{Ag}^{+} .{ }^{106}$ Then, AgDT with a proper nanosilver concentration revealed excellent antibacterial effects against both Escherichia coli and Staphylococcus aureus without significant cytotoxicity to fibroblasts and osteoblasts. ${ }^{106}$

Nanoparticles also have the potential for drug delivery applications in orthopedics. ${ }^{107,108}$ Antimicrobial nanoparticles can be engineered into scaffolds for tissue regeneration purpose. Poly (L-lactic acid) nanofiber scaffolds were synthesized with poly (lactic-co-glycolic acid) nanospheres to provide extended release of the antibiotic doxycycline. ${ }^{109}$ These scaffolds provided sustained antimicrobial activity against $S$. aureus and E. coli over 42 days in bacterial culture and this would also reduce the systemic side effects associated with the antibiotic therapy. ${ }^{110}$ Recent research in oncology has shown selenium to be a powerful potentiat or of chemotherapeutic agents. ${ }^{111}$ When manufactured on the nanometric scale and applied to titanium orthopedic implants, nanophase selenium also appears to inhibit the growth of malignant osteoblasts at the implant-tissue interface. ${ }^{112}$ Nanophase selenium has also been reported to inhibit cancer cells and cause the apoptosis of osteosarcoma cells. ${ }^{113,114}$

\section{Summary}

The emergence of nanotechnology has demonstrated that the tremendous changes in the properties of materials at nanoscale create extraordinary opportunities for biomedical 
applications. Nanomaterials have exhibited many advantages over traditional orthopedic materials in the aspects of biocompatibility, bioactivity, and treatment efficacy, and not surprisingly, these advantages also lay the foundation for the application in the hemostatic and antimicrobial treatments during or after orthopedic surgery.

The aim of nanotechnology-enabled hemostatic or antiinfective agents and materials is providing safe, effective, and economical blood and infection management products. The advances summarized in this article demonstrate that nanotechnology offers a variety of new therapeutic strategies and opportunities for bleeding and infection controls in orthopedic surgery. Further and continuous thought should be given to the improvement of current nanobiomaterials and to the search of even better nanoformulations. ${ }^{115}$ In the near future, nanomaterials need to be further optimized to improve their efficacy and compatibility with the coagulation system, bone, and other host tissues by understanding the role of physicochemical properties of nanomaterials in the biological systems. Also, thorough characterization and standardized evaluation methods are highly desirable to contribute the knowledge base about nanomaterials' effects and fates in human body.

\section{Acknowledgments}

The authors thank National Natural Science Foundation of China (81622032, 51672184, and 51525101), the Scientific Research Foundation for the Returned Overseas Chinese Scholar (2015, 311), the Youth Clinical Research Project of Peking University First Hospital (2017CR06), and projects of Jiangsu Innovation and Entrepreneurship and Natural Science Research of Jiangsu Higher Education Institutions (No.17KJA180011) for supporting this work.

\section{Disclosure}

Drs Yang and Li report grants from Soochow University and grants from Peking University First Hospital during the conduct of the study. The authors report no other conflicts of interest in this work.

\section{References}

1. Shanker DM. Nanomedicine: current status and future prospects. Res Rev J Pharm Nanotechnol. 2015;3(2):46-69.

2. Moghimi SM, Hunter AC, Murray JC. Nanomedicine: current status and future prospects. Faseb J. 2005;19(3):311-330.

3. Hickman DA, Pawlowski CL, Sekhon UDS, Marks J, Gupta AS. Biomaterials and advanced technologies for hemostatic management of bleeding. Adv Mater. 2018;30(4).

4. Ilinskaya AN, Dobrovolskaia MA. Nanoparticles and the blood coagulation system. Part I: benefits of nanotechnology. Nanomedicine. 2013;8(5):773-784.
5. Kim JS, Kuk E, Yu KN, et al. Antimicrobial effects of silver nanoparticles. Nanomedicine. 2007;3(1):95-101.

6. Chekman IS, Ulberg ZR, Gorchakova NO, et al. The prospects of medical application of metal-based nanoparticles and nanomaterials. Lik Sprava. 2011;1(1-2):3.

7. Dallas P, Sharma VK, Zboril R. Silver polymeric nanocomposites as advanced antimicrobial agents: classification, synthetic paths, applications, and perspectives. Adv Colloid Interface Sci. 2011; 166(1-2):119-135.

8. Qu B, Zong-Yu L, Tie-bin S. Application of nanometer burn dressing in burn wound. Heilongjiang Med J. 2003;27(5):343-344.

9. Huang YD, Cheng WL, J M H, Y D W, Gao S, Li D L. A preparation method of regenerated cellulose hemostatic material with surface nanostructure [P]. China, CN 102912622 A. 2013.02.06.

10. Li HB. A preparation method for absorbing multi-functional hemostatic nanomaterials [P]. China, CN101711888 A. 2010.05.26.

11. Liu M, Shen Y, Ao P, Dai L, Liu Z, Zhou C. The improvement of hemostatic and wound healing property of chitosan by halloysite nanotubes. RSC Adv. 2014;4(45):23540-23553.

12. Dong XS, Huang JJ, Zhang L. The research progress of the carbonized hair in traditional Chinese medicine. Guiding J TCM. 2009;15(12): 85-86. Chinese.

13. Zhang JB, Yu L, Liu M, Ma J, Lu Y, Qiu Y. Experimental study on the antibacterial activity of carbon nanofibers. Chin Drug Appl Monit. 2012;5:261-265.

14. Qiu Y, Zhu YY, Sil H, Lu Y, Ma J. Experimental study on the hemostatic effect of carbon nanofiber membrane. Pharm J. 2013;5:428-431.

15. Li XS, Lin W, Xin FL, Yuan Y, Liu CS, Long Da C. Development of a novel CaP-containing mesoporous silica-based xerogels used as hemostatic material with good biodegradability and low heat generation. Adv Mater Res. 2012;340:222-228.

16. Liu CS, Yuan Y. Hemostatic materials and their preparation methods and applications of nano-mesoporous silica gel [P]. China, CN1970090 A. 2007.05.30.

17. Francis HX, Horn JL, inventors; Z-Medica Corp., assignee. Molecular sieve materials having increased particle size for the formation of blood clots. United States patent US20060141060A1. 2006 June 29.

18. Galownia J, Martin J, Davis ME. Aluminophosphate-based, microporous materials for blood clotting. Microporous Mesoporous Mater. 2006; 92(1-3):61-63.

19. Yang Y, Ulung K, Wang X, Horii A, Yokoi H, Zhang S. Designer self-assembling peptide nanomaterials. Nano Today. 2009;4(2): 193-210.

20. Burks S, Spotnitz W. Safety and usability of hemostats, sealants, and adhesives. AORN J. 2014;100(2):160-176.

21. Zhang S, Holmes T, Lockshin C, Rich A. Spontaneous assembly of a self-complementary oligopeptide to form a stable macroscopic membrane. Proc Natl Acad Sci. 1993;90(8):3334-3338.

22. Zhang S, Yokoi H, Gelain F, Horii A. Designer self-assembling peptide nanofiber scaffolds. Semin Cancer Biol. 2005;15(5):413-420.

23. Gelain F, Bottai D, Vescovi A, Zhang S. Designer self-assembling peptide nanofiber scaffolds for adult mouse neural stem cell 3-dimensional cultures. PLoS One. 2005;1(1):e119.

24. Caplan MR, Moore PN, Zhang S, Kamm RD, Lauffenburger DA. Self-assembly of a $\beta$-sheet protein governed by relief of electrostatic repulsion relative to van der Waals attraction. Biomacromolecules. 2000;1(4):627-631.

25. Desii A, Chiellini F, Duce C, et al. Influence of structural features on the self-assembly of short ionic oligopeptides. J Polym Sci A Polym Chem. 2010;48(4):889-897.

26. Gelain F, Unsworth LD, Zhang S. Slow and sustained release of active cytokines from self-assembling peptide scaffolds. J Controlled Rel. 2010;145(3):231-239.

27. Tang F, Zhao X. Interaction between a self-assembling peptide and hydrophobic compounds. J Biomater Sci Polym Ed. 2010;21(5):677-690.

28. Ellis-Behnke RG, Liang Y-X, Tay DKC, et al. Nano hemostat solution: immediate hemostasis at the nanoscale. Nanomedicine. 2006; 2(4):207-215. 
29. Ellis-Behnke RG, Liang Y-X, You S-W, et al. Nano neuro knitting: peptide nanofiber scaffold for brain repair and axon regeneration with functional return of vision. Proc Natl Acad Sci. 2006;103(13):5054-5059.

30. Guo J, Su H, Zeng Y, et al. Reknitting the injured spinal cord by self-assembling peptide nanofiber scaffold. Nanomedicine. 2007;3(4): 311-321.

31. Reed RL 2nd, Merrell RC, Meyers WC, Fischer RP. Continuing evolution in the approach to severe liver trauma. Ann Surg. 1992;216(5): 524-538.

32. Roger S, Talbot D, Bee A. Preparation and effect of $\mathrm{Ca} 2+$ on water solubility, particle release and swelling properties of magnetic alginate films. J Magn Magn Mater. 2006;305(1):221-227.

33. Warrand J. Healthy polysaccharides: the next chapter in food products. Food Tech Biotech. 2006;44(3):355-370.

34. Persson J, Nyström L, Ageland H, Tjerneld F. Purification of recombinant apolipoprotein A-1 Milano expressed in Escherichia coli using aqueous two-phase extraction followed by temperature-induced phase separation. J Chromatogr B Biomed Sci Appl. 1998;711(1-2):97-109.

35. Hama C, Umeda T, Musha Y, Koda S, Itatani K. Preparation of novel hemostatic material containing spherical porous hydroxyapatite/alginate granules. J Ceram Soc Japan. 2010;118(1378):446-450.

36. Ross S. Developing Polyphosphate Bound Nanoparticles for Inducing Quick Blood Clotting [master's thesis]. Chicago, IL: University of Illinois; 2014.

37. Remonda G, Negri V, Morachioli N. Collagen hemostatic felt for local application in the control of surgical bleeding. Annali Dellospedale Maria Vittoria Di Torino. 1982;24(7-12):333-339.

38. Coln D, Horton J, Ogden ME, Buja LM. Evaluation of hemostatic agents in experimental splenic lacerations. Am J Surg. 1983;145(2): 256-259.

39. Fang L, Cong X, Tang W, et al. Novel hemostatic agents based on gelatin-microbial transglutaminase mix. Sci China Life Sci. 2017;60(4): 397-403.

40. Lacerda L, Bianco A, Prato M, Kostarelos K. Carbon nanotubes as nanomedicines: from toxicology to pharmacology. Adv Drug Deliv Rev. 2006;58(14):1460-1470.

41. Radomski A, Jurasz P, Alonso-Escolano D, et al. Nanoparticle-induced platelet aggregation and vascular thrombosis. Br J Pharmacol. 2005; 146(6):882-893

42. Bihari P, Holzer M, Praetner M, et al. Single-walled carbon nanotubes activate platelets and accelerate thrombus formation in the microcirculation. Toxicology. 2010;269(2-3):148-154.

43. Semberova J, De Paoli Lacerda SH, Simakova O, Holada K, Gelderman MP, Simak J. Carbon nanotubes activate blood platelets by inducing extracellular $\mathrm{Ca}^{2+}$ influx sensitive to calcium entry inhibitors. Nano Lett. 2009;9(9):3312-3317.

44. Sokolov AV, Aseychev AV, Kostevich VA, Gusev AA, Gusev SA, Vlasova II. Functionalization of single-walled carbon nanotubes regulates their effect on hemostasis. J Phys Conf Series. 2011;291(1):012054

45. Roy SC, Paulose M, Grimes CA. The effect of TiO2 nanotubes in the enhancement of blood clotting for the control of hemorrhage. Biomaterials. 2007;28(31):4667-4672.

46. Blajchman MA. Substitutes for success. Nat Med. 1999;5(1):17-18.

47. Bertram JP, Williams CA, Robinson R, Segal SS, Flynn NT, Lavik EB. Intravenous hemostat: nanotechnology to halt bleeding. Sci Transl Med. 2009;1(11):11ra22.

48. du K, Shi X, Gan Z. Rapid biomimetic mineralization of hydroxyapatite-g-PDLLA hybrid microspheres. Langmuir. 2013;29(49): 15293-15301

49. du K, Gan Z. Shape memory behaviour of HA-g-PDLLA nanocomposites prepared via in situ polymerization. J Mater Chem B. 2014;2(21): 3340-3348.

50. Song L, Sun L, Jiang N, Gan Z. Structural control and hemostatic properties of porous microspheres fabricated by hydroxyapatite- graftpoly(D,L-lactide) nanocomposites. Compos Sci Technol. 2016;134: 234-241.

51. Davie EW, Fujikawa K, Kisiel W. The coagulation cascade: initiation, maintenance, and regulation. Biochemistry. 1991;30(43):10363-10370.
52. Pyun DG, Yoon HS, Chung HY, et al. Evaluation of AgHAPcontaining polyurethane foam dressing for wound healing: synthesis, characterization, in vitro and in vivo studies. J Mater Chem B. 2015; 3(39):7752-7763.

53. Shen CY, Zhang XM, Li W. Hemostatic materials - Application of Arista $^{\mathrm{TM}}$ in vascular surgery. Chin J Gen Surg. 2006;21(7):532-533.

54. Simak J, De Paoli S. The effects of nanomaterials on blood coagulation in hemostasis and thrombosis. Wiley Interdiscip Rev Nanomed Nanobiotechnol. 2017;9(5):e1448.

55. Wu HZ, Li JZ. Study on the mechanism of coagulation. Thromb Hemost. 1995;1:27-30.

56. Wang XR, Zhou CL. Study on the mechanism of blood coagulation. Meat Res. 2005;11:45-47.

57. Rao SB, Sharma CP. Use of chitosan as a biomaterial: studies on its safety and hemostatic potential. J Biomed Mater Res. 1997;34(1):21-28.

58. Pusateri AE, Mccarthy SJ, Gregory KW, et al. Effect of a chitosan-based hemostatic dressing on blood loss and survival in a model of severe venous hemorrhage and hepatic injury in swine. J Trauma Acute Care Surg. 2003;54(1):177-182.

59. Xiong YB, Han GQ, Liu CX, Lin J, Wang J, Zhao Q. Application of Surgicel in neurosurgery (report of 213 cases). Guizhou Med J. 2006; 30(7):640-641.

60. Brook RD, Rajagopalan S, Pope CA, et al. Particulate matter air pollution and cardiovascular disease: an update to the scientific statement from the American Heart Association. Circulation. 2010;121(21): 2331-2378.

61. Rückerl R, Ibald-Mulli A, Koenig W, et al. Air pollution and markers of inflammation and coagulation in patients with coronary heart disease. Am J Respir Crit Care Med. 2006;173(4):432-441.

62. Baccarelli A, Martinelli I, Zanobetti A, et al. Exposure to particulate air pollution and risk of deep vein thrombosis. Arch Intern Med. 2008;168(9):920-927.

63. Utell MJ, Frampton MW, Zareba W, Devlin RB, Cascio WE. Cardiovascular effects associated with air pollution: potential mechanisms and methods of testing. Inhal Toxicol. 2002;14(12):1231-1247.

64. Greish K, Thiagarajan G, Herd H, et al. Size and surface charge significantly influence the toxicity of silica and dendritic nanoparticles. Nanotoxicology. 2012;6(7):713-723.

65. Nabeshi H, Yoshikawa T, Matsuyama K, et al. Amorphous nanosilicas induce consumptive coagulopathy after systemic exposure. Nanotechnology. 2012;23(4):045101-045156.

66. Napierska D, Thomassen LCJ, Rabolli V, et al. Size-dependent cytotoxicity of monodisperse silica nanoparticles in human endothelial cells. Small. 2009;5(7):846-853.

67. Ilinskaya AN, Dobrovolskaia MA. Nanoparticles and the blood coagulation system. Part II: safety concerns. Nanomedicine. 2013;8(6): 969-981.

68. Lu J, Liong M, Zink JI, Tamanoi F. Mesoporous silica nanoparticles as a delivery system for hydrophobic anticancer drugs. Small. 2007;3(8): 1341-1346.

69. Zhang WZ, Wang GW. Research and development status of nano silver antibacterial materials. New Chem Mater. 2003;31(2):42-44.

70. Castiglioni S, Cazzaniga A, Locatelli L, Maier JAM. Silver nanoparticles in orthopedic applications: new insights on their effects on osteogenic cells. Nanomaterials. 2017;7(6):124.

71. Durán N, Marcato PD, Conti RD, Alves OL, Costa FTM, Brocchi M. Potential use of silver nanoparticles on pathogenic bacteria, their toxicity and possible mechanisms of action. J Braz Chem Soc. 2010;21(6): 949-959.

72. You C, Han C, Wang X, et al. The progress of silver nanoparticles in the antibacterial mechanism, clinical application and cytotoxicity. Mol Biol Rep. 2012;39(9):9193-9201.

73. Wiley B, Sun Y, Mayers B, Xia Y. Shape-controlled synthesis of metal nanostructures: the case of silver. Chem - A Eur J. 2005; 11(2):454-463

74. Choi O, Deng KK, Kim N-J, Ross L, Surampalli RY, Hu Z. The inhibitory effects of silver nanoparticles, silver ions, and silver chloride colloids on microbial growth. Water Res. 2008;42(12):3066-3074. 
75. Xiu Z-M, Zhang Q-B, Puppala HL, Colvin VL, Alvarez PJJ. Negligible particle-specific antibacterial activity of silver nanoparticles. Nano Lett. 2012;12(8):4271-4275.

76. Liu J, Hurt RH. Ion release kinetics and particle persistence in aqueous nano-silver colloids. Environ Sci Technol. 2010;44(6):2169-2175.

77. Fayaz AM, Balaji K, Girilal M, Yadav R, Kalaichelvan PT, Venketesan R. Biogenic synthesis of silver nanoparticles and their synergistic effect with antibiotics: a study against gram-positive and gram-negative bacteria. Nanomedicine. 2010;6(1):103-109.

78. Herzog F, Loza K, Balog S, et al. Mimicking exposures to acute and lifetime concentrations of inhaled silver nanoparticles by two different in vitro approaches. Beilstein J Nanotechnol. 2014;5(1): 1357-1370.

79. Liu MC, Liu MX, Wang XL, Guo GH. The antimicrobial action of nano silver and its application in burn treatment. Chin J Burns. 2017;33(2): $121-125$.

80. Ma X, Chen SW, Wang RM, et al. The effect of nanomaterial bacterial cellulose on the healing of skin trauma in rats. J Organ Eng Res China. 2006;10(37):45-47. Chinese.

81. Zeng RQ, Zheng R. Clinical observation of nanometer silver dressing in treating burn wound. J Modern Hospital. 2006;6(5):26-27.

82. Raveendran P, Fu J, Wallen SL. Completely "green" synthesis and stabilization of metal nanoparticles. J Am Chem Soc. 2003;125(46): 13940-13941.

83. Oluwafemi OS, Lucwaba Y, Gura A, et al. A facile completely 'green' size tunable synthesis of maltose-reduced silver nanoparticles without the use of any accelerator. Colloids Surf B Biointerfaces. 2013; 102(1):718-723

84. Takeshima T, Tada Y, Sakaguchi N, Watari F, Fugetsu B. DNA/Ag nanoparticles as antibacterial agents against gram-negative bacteria. Nanomaterials. 2015;5(1):284-297.

85. Archana D, Singh BK, Dutta J, Dutta PK. Chitosan-PVP-nano silver oxide wound dressing: in vitro and in vivo evaluation. Int $J$ Biol Macromol. 2015;73:49-57.

86. Patil S, Desai N, Mahadik K, Paradkar A. Can green synthesized propolis loaded silver nanoparticulate gel enhance wound healing caused by burns? Eur J Integr Med. 2015;7(3):243-250.

87. Arora S, Tyagi N, Bhardwaj A, et al. Silver nanoparticles protect human keratinocytes against UVB radiation-induced DNA damage and apoptosis: potential for prevention of skin carcinogenesis. Nanomedicine. 2015;11(5):1265-1275.

88. Yuan $\mathrm{C}$, Zhang H, He S. Efficacy and safety of using antifibrinolytic agents in spine surgery: a meta-analysis. PLoS One. 2013;8(11):e82063.

89. Rosenthal BD, Haughom BD, Levine BR. A retrospective analysis of hemostatic techniques in primary total knee arthroplasty: traditional electrocautery, bipolar sealer, and argon beam coagulation. Am J Orthop. 2016;45(4):E187-E191.

90. Marulanda GA, Ulrich SD, Seyler TM, Delanois RE, Mont MA. Reductions in blood loss with a bipolar sealer in total hip arthroplasty. Expert Rev Med Devices. 2008;5(2):125-131.

91. Yun HC, Murray CK, Nelson KJ, et al. Infection after orthopaedic trauma: prevention and treatment. J Orthop Trauma. 2016;30 Suppl 3: S21-S26.

92. Romanò CL, Scarponi S, Gallazzi E, Romanò D, Drago L. Antibacterial coating of implants in orthopaedics and trauma: a classification proposal in an evolving panorama. J Orthop Surg Res. 2015;10(1): $1-11$.

93. Smith WR, Hudson PW, Ponce BA, Rajaram Manoharan SR. Nanotechnology in orthopedics: a clinically oriented review. BMC Musculoskelet Disord. 2018;19(1):67.

94. Besheli NH, Mottaghitalab F, Eslami M, et al. Sustainable release of vancomycin from silk fibroin nanoparticles for treating severe bone infection in rat tibia osteomyelitis model. ACS Appl Mater Interfaces. 2017;9(6):5128-5138.

95. Hazer DB, Sakar M, Dere Y, Altnkanat G, Ziyal MI, Hazer B. Antimicrobial effect of polymer-based silver nanoparticle coated pedicle screws - experimental research on biofilm inhibition in rabbits. Spine. 2015;41(6):E323-E329.
96. Annabi N, Tamayol A, Shin SR, Ghaemmaghami AM, Peppas NA, Khademhosseini A. Surgical materials: current challenges and nanoenabled solutions. Nano Today. 2014;9(5):574-589.

97. Meddahi-Pellé A, Legrand A, Marcellan A, Louedec L, Letourneur D, Leibler L. Organ repair, hemostasis, and in vivo bonding of medical devices by aqueous solutions of nanoparticles. Angewandte Chemie International Edition. 2014;53(25):6369-6373.

98. Widmer AF. New developments in diagnosis and treatment of infection in orthopedic implants. Clin Infect Dis. 2001;33(s2):S94-S106.

99. Bacakova L, Filova E, Parizek M, Ruml T, Svorcik V. Modulation of cell adhesion, proliferation and differentiation on materials designed for body implants. Biotechnol Adv. 2011;29(6):739-767.

100. Lu T, Qiao Y, Liu X. Surface modification of biomaterials using plasma immersion ion implantation and deposition. Interface Focus. 2012;2(3):325-336.

101. Singh AV, Vyas V, Patil R, et al. Quantitative characterization of the influence of the nanoscale morphology of nanostructured surfaces on bacterial adhesion and biofilm formation. PLoS One. 2011; 6(9):e25029.

102. Asharani PV, Glk M, Hande MP, Valiyaveettil S. Cytotoxicity and genotoxicity of silver nanoparticles in human cells. Arch Toxicol. 2011;85(7):743-750

103. Zhou JD, Wang SH, Liu R, et al. Study of the biological effectiveness of a nanosilver-epidermal growth factor sustained-release carrier. Exp Ther Med. 2013;5(4):1231-1235.

104. Ni GX, Chiu KY, Lu WW, et al. Strontium-containing hydroxyapatite bioactive bone cement in revision hip arthroplasty. Biomaterials. 2006; 27(24):4348-4355.

105. Nakano M, Hirano N, Matsuura K, et al. Percutaneous transpedicular vertebroplasty with calcium phosphate cement in the treatment of osteoporotic vertebral compression and burst fractures. J Neurosurg. 2002;97(3 Suppl):287-293.

106. Sun H, Wen X, Zhang X, et al. Biocompatible silver nanoparticlemodified natural diatomite with anti-infective property. J Nanomater. 2018;2018:1-8.

107. Tautzenberger A, Kovtun A, Ignatius A. Nanoparticles and their potential for application in bone. Int J Nanomedicine. 2012;7(7):4545-4557.

108. Frost SJ, Mawad D, Hook J, Lauto A. Micro- and nanostructured biomaterials for sutureless tissue repair. Adv Healthc Mater. 2016;5(4): 401-414.

109. Feng K, Sun H, Bradley MA, Dupler EJ, Giannobile WV, Ma PX. Novel antibacterial nanofibrous PLLA scaffolds. $J$ Control Release. 2010;146(3):363-369.

110. Johnson CT, García AJ. Scaffold-based anti-infection strategies in bone repair. Ann Biomed Eng. 2015;43(3):515-528.

111. Holmgren A, Nilsonne G, Sun X, Nyström C. Selenite in cancer therapy: a commentary on "Selenite induces apoptosis in sarcomatoid malignant mesothelioma cells through oxidative stress". Free Radic Biol Med. 2006;41(6):862-865.

112. Tran PA, Sarin L, Hurt RH, Webster TJ. Titanium surfaces with adherent selenium nanoclusters as a novel anticancer orthopedic material. J Biomed Mater Res A. 2010;93(4):1417-1428.

113. Sullivan MP, Mchale KJ, Parvizi J, Mehta S. Nanotechnology: current concepts in orthopaedic surgery and future directions. Bone Joint $J$ 2014;96-B(5):569-573.

114. Shi Z, Huang X, Liu B, Tao H, Cai Y, Tang R. Biological response of osteosarcoma cells to size-controlled nanostructured hydroxyapatite. J Biomater Appl. 2010;25(1):19-37.

115. Garimella R, Eltorai AE. Nanotechnology in orthopedics. J Orthop. 2017;14(1):30-33

116. Sotiriou GA, Teleki A, Camenzind A, et al. Nanosilver on nanostructured silica: antibacterial activity and $\mathrm{Ag}$ surface area. Chem Eng $J$. 2011;170(2-3):547-554. 


\section{Publish your work in this journal}

The International Journal of Nanomedicine is an international, peerreviewed journal focusing on the application of nanotechnology in diagnostics, therapeutics, and drug delivery systems throughout the biomedical field. This journal is indexed on PubMed Central, MedLine, CAS, SciSearch $\AA$, Current Contents $\AA /$ Clinical Medicine,
Journal Citation Reports/Science Edition, EMBase, Scopus and the Elsevier Bibliographic databases. The manuscript management system is completely online and includes a very quick and fair peer-review system, which is all easy to use. Visit http://www.dovepress.com/ testimonials.php to read real quotes from published authors.

Submit your manuscript here: http://www.dovepress.com/international-journal-of-nanomedicine-journal 